\title{
RUPTURE PROCESS OF THE JUNE 28, 1992 BIG BEAR EARTHQUAKE
}

\author{
L. E. Jones \\ Seismological Laboratory, California Institute of Technology, Pasadena, California \\ S. E. Hough \\ U. S. Geological Survey, Pasadena, California \\ D. V. Helmberger \\ Seismological Laboratory, California Institute of Technology, Pasadena, California
}

\begin{abstract}
The June 28, 1992 Big Bear earthquake in southern California was assumed to have ruptured along a northeast-trending plane, as suggested by long-term aftershock distribution. No surface rupture was found, however, and mainshock locations determined from both strong motion and TERRAscope data are mutually consistent and do not lie on the assumed fault plane. An integrated study involving waveform modeling, directivity and seismicity analyses suggests a complex rupture pattern, with signifcant short- and long-period energy propagating northwest along the presumed conjugate fault-plane.
\end{abstract}

\section{Introduction}

The $M_{w}=7.3$ Landers earthquake of 11:58 GMT, June 28, 1992 was followed by tens of thousands of aftershocks, [Kanamori, et al., 1992]. The largest was the $M_{w} 6.3-6.5$ Big Bear earthquake which occurred three hours later and was associated with significant damage in Big Bear City. The Big Bear event is associated with its own fore- and aftershock sequences, including several in the $M 4-5$ range. We will subsequently refer to this event as a 'mainshock'.

A focal mechanism for the Big Bear mainshock was obtained by a grid-search method [ Zhao and Helmberger, 1993] and is plotted on the location map shown in Figure 1. It agrees with the mechanisms obtained from long-period regional and teleseismic surface wave data [Thio, personal comm.,1992]. The source parameters and locations of the 14:43 GMT foreshock, the mainshock and selected aftershocks, all obtained via the grid-search method, are listed in Table 1. No surface rupture was initially observed for this event, but aftershocks generally delineate the extent of an earthquake rupture and appear to line up along the NE-striking nodal plane.

Focal plane solutions for selected aftershocks of magnitude greater than 3.9 are shown on Figure 1. The sequence appears to be dominated by deeper to intermediate $(7-17 \mathrm{~km})$ depth strike-slip events on trends parallel to both planes of the mainshock source mechanism. Shallower thrust-type events are observed at the western ends of aftershock trends, as well as along the frontal fault to the north. Events which occurred within the first 24 hours of the mainshock are shown as filled stars on Figure 1. Open stars show locations of later aftershocks of magnitude greater than 3.9. Larger (filled and open) stars

\section{Copyright 1993 by the American Geophysical Union.}

indicate events with magnitude greater than 3.9; smaller filled stars indicate locations of events of magnitude 1.9 to 3.9. Focussing on aftershocks occuring within a day of the

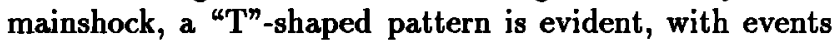
along both the presumed NE-striking rupture plane and the NW-striking antithetic plane.

The SCSN location of the Big Bear event was presumed unreliable due to a M4 foreshock that occurred 40 seconds before the mainshock, but this foreshock is too small to yield appreciable amplitudes on the strong-motion recordings. The network location determined from just the strong motion data of $34^{\circ} 12.36^{\prime} N, 116^{\circ} 50.11^{\prime} W$ (i.e., several km off the presumed rupture plane) yields a low rms residual of $0.15 \mathrm{sec}$ and appears to be well resolved [ $\mathrm{L}$. Wald, personal comm., 1992]. This location is consistent with a location obtained from TERRAscope data: $34^{\circ} 12.6^{\prime} \mathrm{N}, 116^{\circ}$ $50.4^{\prime} W$. Both locations are significantly distinct from the immediate foreshock location, $34^{\circ} 9.94^{\prime} N, 116^{\circ} 49.38^{\prime} \mathrm{W}$. In this paper, we analyze data from four of six TERRAscope stations to determine the rupture characteristics of the Big Bear event.

\section{Analysis}

\section{Empirical Greens function analysis}

Numerous studies have demonstrated that the empirical Green's function (eGf) method, whereby complex path effects are deconvolved from an earthquake recording using a nearby smaller earthquake, can provide accurate estimates of source parameters [ Bakun and Bufe, 1975; Mori and Hartzell, 1990]. Empirical Green's functions can be used either with inverse methods to deconvolve source properties (e.g Mori and Hartzell, 1990), or in forward modeling efforts to 'construct' a large earthquake from one or more smaller events [Wennerberg, 1990]. Ideally, an eGf should be at the same location and have the same source mechanism as the event investigated, to insure that both events have the same source and propagation characteristics. However, with longer period data, the method has been applied successfully using eGf-mainshock pairs that are separated by as much as a few $\mathrm{km}$ [Ammon, et al., 1992]. For the Big Bear event, we select the $M 5.2$ foreshock that occurred at 14:43 GMT on 6/28/92, the $M 4.4$ aftershock which occurred at 17:48 GMT on 6/28/92 and the M4.0 aftershock which occurred at 13:52 GMT on $8 / 24 / 92$. The foreshock is approximately $7 \mathrm{~km}$ southwest of the mainshock, has a depth of $12 \mathrm{~km}$ (from grid-search solution) but has a similar mechanism and similar waveforms (Figures 2, 3a, and Table 1). Likewise, the two aftershocks have similar mechanisms, but locate roughly 8.8 
TABLE 1. Big Bear Events

\begin{tabular}{cccccccc}
\hline \multirow{2}{*}{ Date } & & \multicolumn{3}{c}{ Location } & & & \\
\cline { 3 - 7 } & & $\begin{array}{c}\text { Depth } \\
\mathrm{km}\end{array}$ & $\begin{array}{c}\text { Lat } \\
{ }^{\circ} \mathrm{N}\end{array}$ & $\begin{array}{c}\text { Lon } \\
{ }^{\circ} \mathrm{W}\end{array}$ & strike & dip & rake \\
\hline 9206281443 & 5.2 & 12 & 34.16 & 116.85 & 210 & 86 & 330 \\
9206281505 & 6.3 & $3-8$ & 34.21 & 116.83 & 321 & 86 & 200 \\
9206281748 & 4.3 & 7 & 34.22 & 116.75 & 324 & 90 & 200 \\
9208172041 & 4.8 & 14 & 34.18 & 116.87 & 285 & 65 & 150 \\
9208241351 & 4.0 & 8 & 34.28 & 116.78 & 330 & 75 & 178 \\
\hline
\end{tabular}

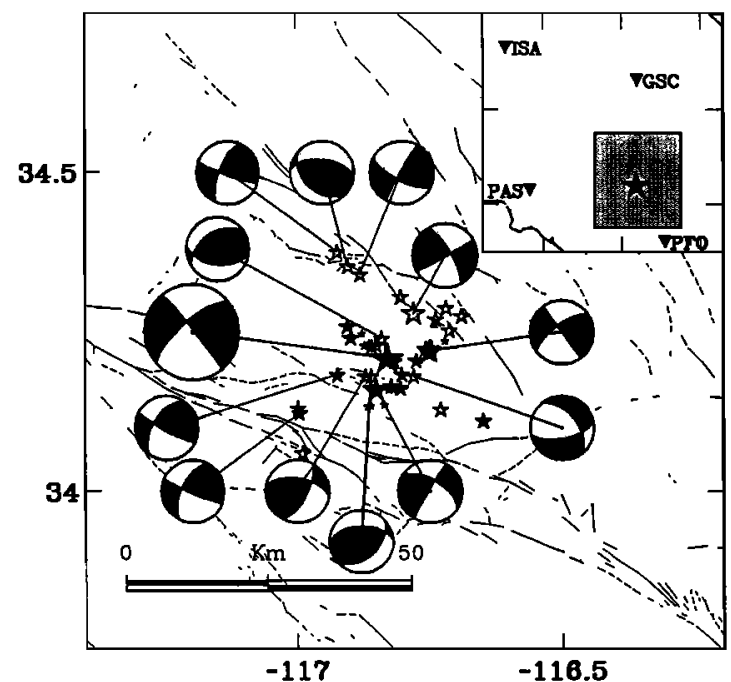

Fig. 1. Map showing the location of the Big Bear earthquake (large star) and the location of other $M>3.9$ aftershocks in the sequence (smaller stars).

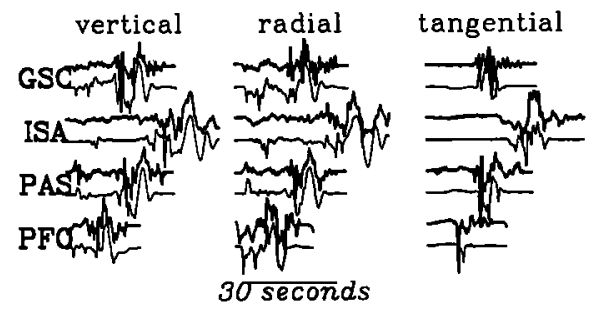

Fig. 2. Modelling results for the 14:43 gmt foreshock used as a Master event in this paper. The synthetics are from the Standard Southern California Model, and are generated via the frequency-wavenumber integration method. A source-depth of $12 \mathrm{~km}$ and a 1-second triangle sourcetime function are assumed. The data are modeled broadband with only minimal filtering (bandpass filtering from 0.02 to $7 \mathrm{~Hz}$ ).

$\mathrm{km}$ east and $7.4 \mathrm{~km}$ northeast of the mainshock, and at depths of 7 and $8 \mathrm{~km}$, respectively.

Empirical Green's function deconvolutions for source time functions are unstable for myriad reasons [ Mori and Hartzell, 1990; Ammon, et al., 1992 ]. We have instead applied a forward modeling approach whereby eGf data are convolved with source time functions that contain one or more realistic pulses. This convolution insures that the frequency content of the eGf is properly scaled up to higher magnitudes, and is conceptually analagous to a frequencydomain method presented by Wennerberg, [1990].

While the foreshock is modelled satisfactorily with a standard model, and assuming a point source (Figure 2), we find that mainshock waveform complexity cannot be fit with a simple, single-pulse source-time function (Figures $3 \mathrm{a}$ and $3 \mathrm{~b}$ ), and that substantially better results are obtained with the addition of a second pulse: For TERRAscope stations PFO and ISA, a third sub-event is also suggested (Figure 3b). Figure 3a presents the TERRAscope mainshock data along with the preferred empirical Green's function modeling results. Since ISA and PFO are roughly on $P$-wave nodes and $S H$-wave maxima, we model the tangential component for these two stations. Since PAS and GSC are on or near $S H$ nodes, we focus on the vertical component of displacement for these stations. These records require source-time functions composed of two pulses (Figure 3b). The modelling results match many of the more salient features of the observations. Inferred source-time functions are shown in Figure 3b. Pulse widths cannot be interpreted in terms of source-time function durations because they indicate pulse width relative to that of the eGf. Note that amplitudes are relative to the amplitude ratios of the mainshock and empirical Green's function at each station. Given the effective source-time functions we derive, and the moment of the foreshock $\left(9.73 \times 10^{23}\right.$ dyne$\mathrm{cm}$ ), we estimate a moment of $5.3 \times 10^{25}$ for the mainshock; equivalent to $M_{w}=6.48$.

Assuming that the two pulses at stations GSC and PAS correspond to the first two pulses at stations ISA and PFO, we can solve for a relative location of the second sub-event. Assuming further that the first sub-event occurs at the SCSN-determined epicenter and that the sub-event spacing is small compared to the event-station spacings, the sub-event spacings can be predicted adequately with a second sub-event occuring 3.7 seconds after the first, roughly $3.2 \mathrm{~km}$ and $15^{\circ}$ east of south from the first sub-event. Thus, the inferred sub-event spacing towards PFO is 3.7 seconds minus the travel time projected on the azimuth towards PFO, while the inferred spacing towards ISA is roughly 3.7 seconds plus the same amount.

The location of the third hypothesized sub-event cannot be constrained from our results. However, the fact that a third sub event appears to be required only at stations PFO and ISA suggests that this sub-event was either to the NE or SW of the second sub-event, along the presumed mainshock rupture plane. Stations PFO and ISA are broadside to this $\mathrm{NE}$-striking plane and would be expected to observe a sub-event along the plane more distinctly than would stations at other azimuths.

\section{Directivity Analysis}

The above analysis constrains only relative subevent geometry; nothing about rupture direction(s) is assumed or inferred. To investigate directivity, we compare short- and long-period amplitudes of the mainshock with amplitudes 

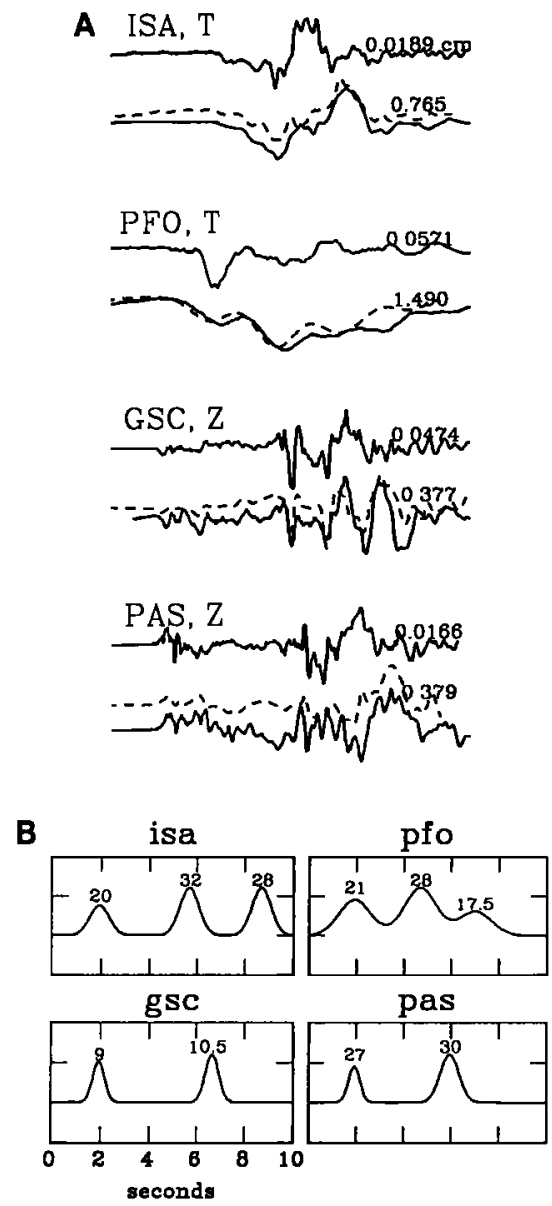

Fig. 3. a, The four panels show results for the four TERRAscope stations used in this study. In each panel, the top trace represents the "master event" or raw eGF data from the June 28, 1992 14:43 foreshock. The dashed trace represents the convolution of the eGF with the preferred source-time function. The bottom, solid trace is the mainshock data. $\quad b$, Preferred source-time functions for choice of the June 28, $199214: 43 \mathrm{gmt}$ foreshock $\left(M=9.73 \times 10^{23}\right)$ as empirical Green's function.

of smaller events in the sequence. As discussed by Helmberger, et al., [1992], this type of comparison can be used to indicate the rupture direction. Analogous to the empirical Green's function method, this amplitude analysis isolates source properties of the mainshock by assuming path effects and source radiation pattern are similar between the mainshock and the nearby smaller event.

For this study we have used the the 6/28/92 14:43 foreshock, the $6 / 28 / 9217: 48$ and the $8 / 24 / 92$ aftershocks as 'master' events. We have also included the 8/17/92 M4.8 aftershock, the source parameters and location of which are listed in Table 1. Again, we examine the tangential component of displacement for ISA and PFO, and the vertical component of motion for GSC and PAS.

The broadband displacement records (integrated from acceleration in the case of the mainshock, and from velocity in the case of the 'master' events) are convolved with a short-period Wood-Anderson response, and the ratios of the peak short-period amplitudes for the tangential component (all 4 stations) are shown plotted against stationevent azimuth in Figure 4a. The average station-event az- imuth is indicated above the top curve, and all four curves are normalized such that the amplitude at GSC is $\mathbf{1 0 0}$. The short-period amplitudes are highest in the direction of ISA, and taper off to minima about 180 degrees azimuth from ISA, i.e., in the approximate direction of PFO. The solid curve represents a simple theoretical computation for the doppler-shift effects on amplitude, assuming rupture towards station ISA and a rupture velocity of 0.7 times the crustal shear wave velocity [ Aki and Richards, 1980]. The same comparison for the vertical components is shown in Figure 4b. Again, amplitude ratios at ISA are consistently much higher, and ratios at stations PAS and GSC behave more as we might expect them to from the theoretical computation (unbroken line).

Similar short-period analysis was performed for the $06 / 28 / 9214: 43$ foreshock, using the $6 / 28 / 9217: 48$ aftershock, the 08/17/92 aftershock and the 08/24/92 aftershock as 'master events.' These results are shown in Figure 4c. In this case, it is evident that energy release was primarily to the north, in the direction of station GSC.

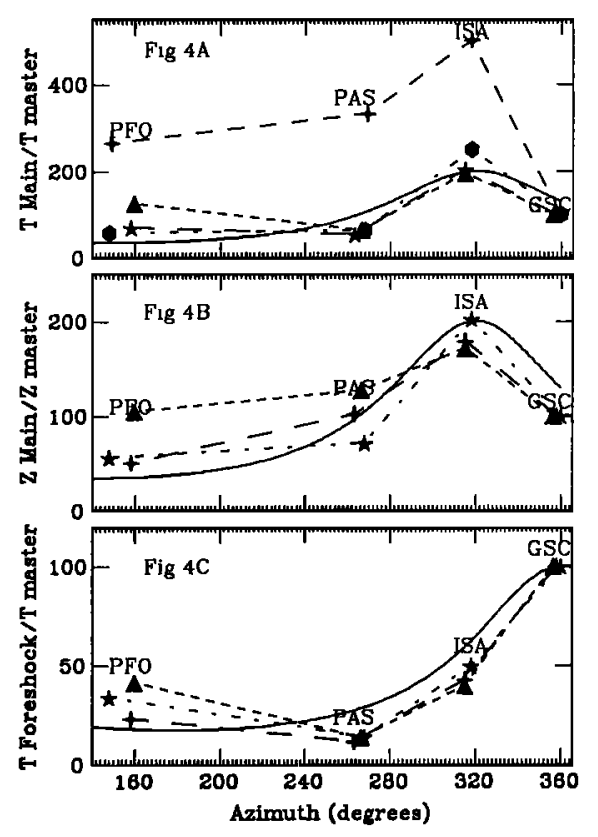

Fig. 4. a, Short-period Wood-Anderson amplitude ratios for the tangential component of displacement. Broadband TERRAscope data was band-pass filtered, rotated and convolved with a Wood-Anderson Short-period response. Amplitudes of the mainshock tangential components for the stations PFO, PAS, ISA and GSC are shown; divided by the short-period amplitudes of the "master" event. The solid line is a theoretical doppler-shift curve assuming propagation towards station ISA at a rupture velocity of 0.7 times the crustal shear wave velocity of 2.6 $\mathrm{km} / \mathrm{s}$. b, Short-period Wood-Anderson amplitude ratios for the vertical component of displacement. Values are normalized so that amplitude ratios at GSC are equal to 100 for each mainshock/master event pair. $c$, Short-period Wood-anderson ratios for the tangential component of displacement, 14:43 foreshock; normalized as above. The master events used are the June 28, 1992 17:48 gmt aftershock, the August 17, 1992 aftershock, and the August 24, 1992 aftershock. The solid line is a theoretical doppler-shift curve for propagation towards station GSC. 
Discussion

Our investigations indicate that the Big Bear earthquake is characterized by a complex rupture pattern, with two to three sub-events on two conjugate fault planes. The combined results (i.e., event epicenter, sub-event geometry, and directivity) suggest the following scenario for the sequence: The 14:43 M5.2 foreshock occurred near $34^{\circ} 10^{\prime} N, 116^{\circ} 49^{\prime} \mathrm{W}$ and ruptured roughly northward. A smaller, M4.0 foreshock occurred in a similar location at 15:04 GMT. Rupture during the Big Bear earthquake began at 15:05 GMT at $34^{\circ} 12.4^{\prime} N, 116^{\circ} 50.1^{\prime} \mathrm{W}$, north of the foreshocks, and ruptured to the northwest. A few seconds later, rupture initiated along the NE-striking plane close to the location of the foreshocks.

High relative amplitudes at station ISA to the northwest suggest that substantial moment release occurred along this nodal plane. We note that these amplitudes cannot be explained as an artifact of bilateral rupture along the NE-striking plane because then PFO would be expected to have similar high amplitudes, which is not observed. The previous presumption of a NE-striking mainshock rupture plane is attributed to an overall (long term) aftershock distribution that is misleading. It is not necessarily true that regions of high mainshock slip will correspond to regions of the most intense aftershock activity; in fact it has been suggested that areas of high slip and/or total stress release correlate instead with sparse aftershock activity [ Beroza, 1991]. Moreover, several lines of evidence suggest that the Big Bear event was, overall, a high stress drop earthquake [ Jones and Helmberger, 1993], and the NW-trending rupture could be shorter than the NE-trending rupture if the former were particularly high stress drop.

Our results have several implications for the tectonic structure of the Big Bear region. A NW-striking 'Big Bear' fault would be parallel to both the Helendale fault to the NE and to the distributed faults in the Mojave shear zone [Dokka, et al., 1992], suggesting that the fabric of the Mojave shear zone may persist under the San Bernardino Mountains (SBM). The complex nature of the Big Bear rupture, the diversity of aftershock mechanisms, and the distributed locations of the aftershocks further suggest that the SBM may be characterized by pervasive conjugate (NE/NW) fault sets bounded to the north by the frontal thrust of the SBM and to the south by the San Andreas fault.

The second implication of our results concerns the effect of the Landers/Big Bear sequence on the nearby San Andreas Fault (SAF). Several studies (e.g., Stein, et al., 1993; Harris and Simpson, 1993) have shown that stress changes caused by the Landers earthquake and the presumed (i.e., northeast trending) Big Bear rupture would tend to move the SAF closer to failure both along a southern segment (Indio to Salton Sea) and along the San Bernardino segment, while reducing normal stress on the SAF in between the two segments. However, the NW-striking 'Big Bear' fault is roughly parallel to the San Bernardino segment of the SAF and would thus tend to reduce its shear stress. Although a definitive partitioning of moment release on the two faults is beyond the scope of our investigations our results suggest that substantial moment release did occur on the NE-trending fault plane and that the effects of this event on the nearby SAF should be re examined.
Acknowledgments. We thank Lisa Wald for providing us the SCSN location of the Big Bear event, Egill Hauksson for providing aftershock relocations. Contribution number 5271, Division of Geological and Planetary Sciences, California Institute of Technology, Pasadena, CA 91125.

\section{References}

Ammon, C. J., A. A. Velasco, and T. Lay, Rapid estimation of rupture directivity: Application to the 1992 Landers $\left(M_{s}=7.4\right)$ and Cape Mendocino $\left(M_{s}=7.2\right)$, California earthquakes, Geophys. Res. Lett, 20, 97-100, 1993.

Kanamori, H., H-K. Thio, D. Dreger, E. Hauksson, and T. Heaton, Initial Investigation of the Landers, California, earthquake of 28 June 1992 using TERRAscope, Geophys. Res. Letters, 19, 2267-2270, 1992.

Zhao L-S., and D. V. Helmberger, Source Estimation from Broadband Regional Seismograms, submitted to Bull. Seism. Soc. Am., January, 1993.

Thio, H-K., personal communication, 1992.

L. Wald, personal communication, 1993.

Bakun, W. H., and C. G. Bufe, Shear wave attenuation along the San Andreas fault zone in central California, Bull Seism. Soc. Am., 65, 439-459, 1975.

Mori, J. and S. Hartzell, Source inversion of the 1988 Upland, California earthquake: determination of fault plane for a small event, Bull. Seism. Soc. Am., 80, 507-518, 1990.

Wennerberg, L., Stochastic summation of empirical Green's functions, Bull. Seism. Soc. Am., 80, 1418-1432, 1990.

Helmberger, D.V., R. Stead, P. Ho-Liu, and D. Dreger, Broadband modelling of regional seismograms, Imperial Valley to Pasadena, Geophys. J. Int.,110, 42-54, 1992.

Aki, K. and Richards, P., Quantitative Seismology, Theory and Methods, W. H. Freeman and Company, New York, Vol. 2, 807-812, 1980.

Beroza, G. C. and P. Spudich, Linearized inversion for fault rupture behavior: application to the 1984 Morgan Hill, California earthquake, J. Geophys. Res., 93, 6275-6296, 1988.

Jones L. E., and D. V. Helmberger, Broadband modeling of aftershocks from the Landers, Big Bear and Joshua Tree events, (abstracts), Eos, Transactions, 73, 383, 1992.

Dokka, R. K., D. F. MacConnell and J. P. Ford, Active and inactive faults of the northern Mojave Desert Block: Implications for strain partitioning in the Eastern California Shear Zone, (abstracts), Eos, Transactions, 73, 363, 1992.

Stein, R. S., G. C. P. King, and J. Lin, Change in failure stress on the Southern San Andreas fault system caused by the 1992 Magnitude=7.4 Landers earthquake, Science, 258, 1328-1332, 1992.

Harris, R. A., and Simpson, R. W., Changes in static stress on southern California faults after the 1992 Landers earthquake, Nature, 360, 251-254, 1992.

L. Jones and D. Helmberger, Seismological Laboratory 252-21, California Institute of Technology, Pasadena CA 91125.

S. Hough, U. S. Geological Survey, Pasadena, CA 91106.

(Received: June 9, 1993; accepted: July 22, 1993) 